\title{
IMPACT OF SOCIO-DEMOGRAPHIC FACTORS ON EMPLOYEE'S PERCEPTION OF ORGANIZATIONAL COMMUNICATION EFFECTIVENESS
}

\author{
Sllavka Kurti ${ }^{304}$ \\ Petrit Dollani ${ }^{305}$ \\ Fatjola Lubonja ${ }^{306}$
}

https://doi.org/10.31410/itema.2018.863

\begin{abstract}
The organization in its simplified sense is a group of individuals who interact and collaborate to achieve common goals. From this point of view, organizations are primarily communication entities [6]. Effective communication is the cornerstone of the existence of any organization regardless of size, ownership or legal form. Trying to meet its objectives, it is essential for the organization to develop effective communication systems. Without effective communication, managers will not be able to perform properly any of the managerial functions (planning, organizing, guiding, motivating or controlling their employees). Put simply, communication is the component that enables the existence of the organization itself.

Various research has been carried out about the importance of effective organizational communication, aiming not only on identifying the positive relationship with satisfaction, confidence, engagement [4], motivation of the employees and further to the success of the organization, but also warning and making aware managers in addressing obstacles to the implementation of an effective communication system. Therefore, different scholars suggest that organizations constantly should carry out audits to evaluate the effectiveness of internal communication and to verify whether it is timely, correct, and accurate, as appropriate.

Following studies of the importance of effective organizational communication, this paper, through the primary quest for quantitative data, is intended to go further by focusing on perceptions of employees regarding the effectiveness of internal organizational communication. The paper begins with a brief and concentrated review of the literature on the importance of organizational communication effectiveness, to go further with the quantitative data analysis, collected through questionnaires to different employees from the private sector. The main objective of the paper is to assess whether employee demographic factors, such as gender, age, and years of work experience, have an impact on their perceptions of effective communication in the organization, by focusing on effective communication channels used in the organization, as well as the barriers that potentially hinder the realization of effective communication. In this way, the results of this study aim to make managers aware not only of monitoring the effectiveness of communication in the organization, but also to be able to tailor channels and address the obstacles to implement a system of effective communication, regarding the demographic characteristics of their staff.
\end{abstract}

Keywords: effective organizational communication, demographic factors, barriers, channels

\footnotetext{
${ }^{304}$ Faculty of Economy, University of Tirana, Tirana, Albania

${ }^{305}$ Faculty of Economy, University of Tirana, Tirana, Albania

306 Albanian Road Authority. PhD Candidate, Agricultural University of Tirana, Faculty of Economy and Agriculture, Tirane, Albania
} 
"The ability to communicate clearly and confidently accounts for $85 \%$ of your business success" Brian Tracy

\section{Introduction}

$\mathrm{N}$ owadays, all organizations operate in a dynamic and complex environment. To survive in such an environment and to gain competitive advantage, their decision-makers need to be aware of and understand the vital role of organizational communication. Anderson [2] among the conclusion of his study goes further and argues that today for all organizations, effective communication is a necessity. Numerous studies conclude that the implementation of an effective communication system brings to the organization many benefits, straightforward or indirect, short-term or long-term. Trying to achieve effective organizational communication, among other things, a manager should pay attention to the means of communication used and potential barriers that prevent the flow of information efficiently in all parts of the organization, where his presence is necessary, in right time.

\section{Literature review}

The presence of an effective communication system is very crucial and often determines the organization's growth in all aspects, and as such cannot be overlooked by the managers. Harris and Nelson [10] argue that the sustainability of an organization is also based on the extent to which effective communication between employees is present and the kind of relationship established, thus avoiding the unstructured conflicts.

Malmelin [15] considers communication as an intangible asset of an organization, which if appropriately adapted to a system that supports the integration of different dimensions of internal organizational communication, will generate value, and sees it as the key element defining the future of a business. By improving the quality of communication, management can increase employee engagement [16] and enable each and every part of the organization to concentrate on responding to requests; otherwise the organization can potentially face a future with loss of customers until bankruptcy [11].

Different scholars, in an effort to re-emphasize the importance of communication claim that organizational communication is an effective means of motivating employees [14] and has an important impact on the extent to which employees believe their managers [4], the degree of commitment to the organization and the identification with it, reduces their level of insecurity and gives them the opportunity to make better decisions.

The importance of effective communication in the organization cannot be overlooked, considering the fact that employees or managers regardless of the hierarchical level should interact with each other in an effort to meet organizational objectives. Internal communication can be defined from an operational point of view as an exchange of formal and/or informal messages between employees, managers within an organization, aiming at simplification toward the realization of collective interest and unstructured cooperation within the organization [7].

Tubbs and Moss [17] in their research concluded that there is a correlation between the quality of communication and overall performance within the organization. Apparently the lack of effective communication is an indisputable obstacle to a successful organizational performance. 
This statement highlights the importance that managers should devote particularly to the implementation of effective communication systems within the organization. If one needs to identify the characteristics of effective communication, they can be summarized in: a) the quality and the way the message is communicated, b) achieving the desired result c) the right time [12]. Key elements in achieving effective communication in the organization are obviously the used communication channels. According to Barry and Fulmer [3], the first step to claiming an effective communication system consists in matching the communication channels with the purpose of communication. The importance of the channels of communication seems to be neglected by managers, despite studies that show that effective managers, compared to those who are less effective, tend to use more "information-rich communication channels" [1].

Important elements that affect the effective communication system are barriers (obstacles). Performance within an organization can be significantly improved by sharing information with employees and including them in policy making. This might not be attained if barriers that become an obstacle to effective organizational communication are not addressed. They can be of different forms, and referred to Zaineb [21] the most common forms of communication barriers in organizations are categorized into what are known as perceptual, emotional, linguistic, cultural and physical or structural barriers.

\section{Methodology}

The primary purpose of this paper is to point out if there are differences in perception of employees for effective communication in an organization, based on some of their sociodemographic characteristics. Specifically, the focus of research questions will be:

1) Do sociodemographic characteristics of employees affect their perceptions of effective channels in organizational communication?

2) Do sociodemographic characteristics of employees affect their perceptions of effective organizational communication barriers?

This study included 85 different employees, mainly in the positions of specialist and low level managers, employed in private businesses operating in the service sector. The instrument used was a questionnaire, which is divided into three parts, in the first there are sociodemographic data, such as gender, age, level of education and years of work experience, to further explore questions to evaluate their perception regarding the communication channels as well as the barriers to effective communication. This paper has a descriptive nature and is based solely on the evidence whether differences in sociodemographic factors and perceptions of effective communication in the organization exist or not, and the data have been processed with the excel program. It should be underlined as a limitation, the number of the employees and organizations involved in the study, which implies that drawn conclusions could not be generalized for majority of organizations.

\section{Discussion of findings}

The following is a brief description of the socio-demographic data of the respondents, which are generated from the first section of the questionnaire, and presented graphically. The largest percentage of respondents are women with $62 \%$, with the largest part (48\%) having 6 to 10 years of work experience (Graph 3) and more than half of them (53\%) are in the age group 26 to 45 (Graph 4). They are employed in private businesses operating in the service sector, in the city of Durres, Albania. Constantly, the employees involved in the study are employed in 
branches of second tier banks, customs agencies, insurance agencies and international transport firms. Their distribution is given in Graph 2.

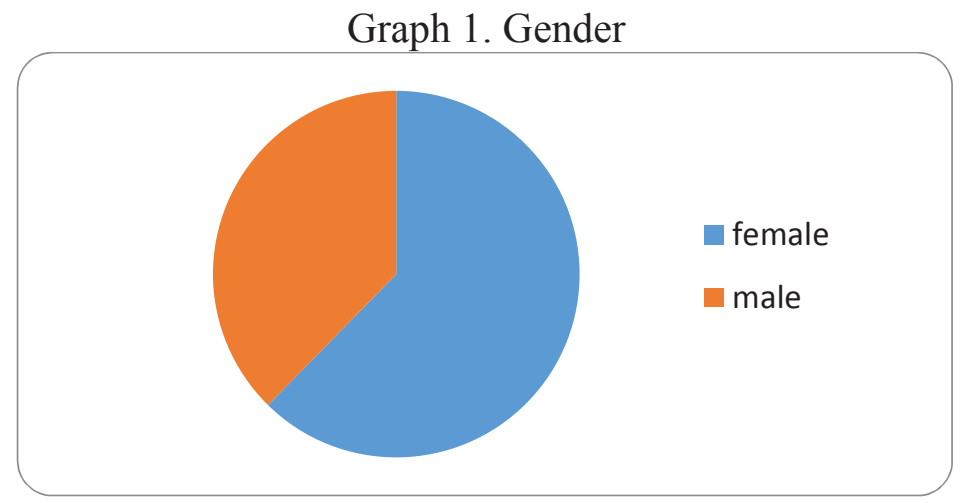

Graph 2. Employing organizations

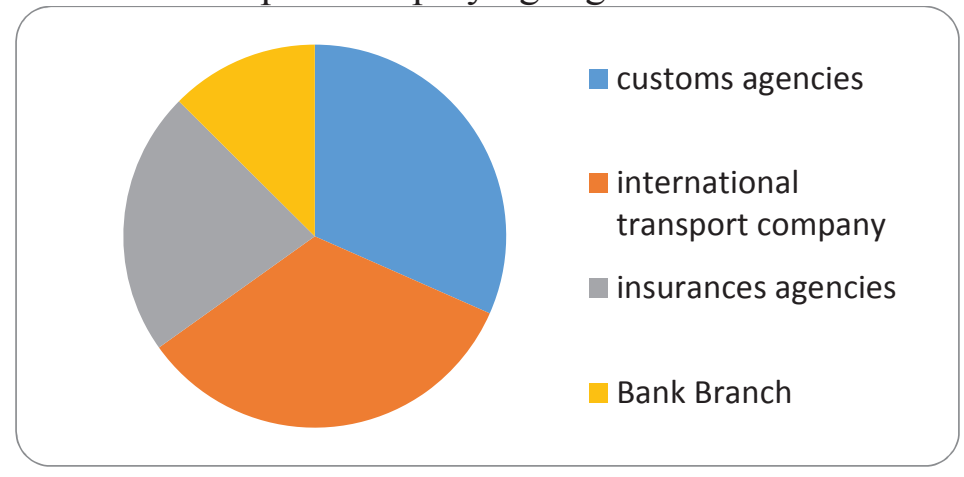

Graph 3. Years of work in organization

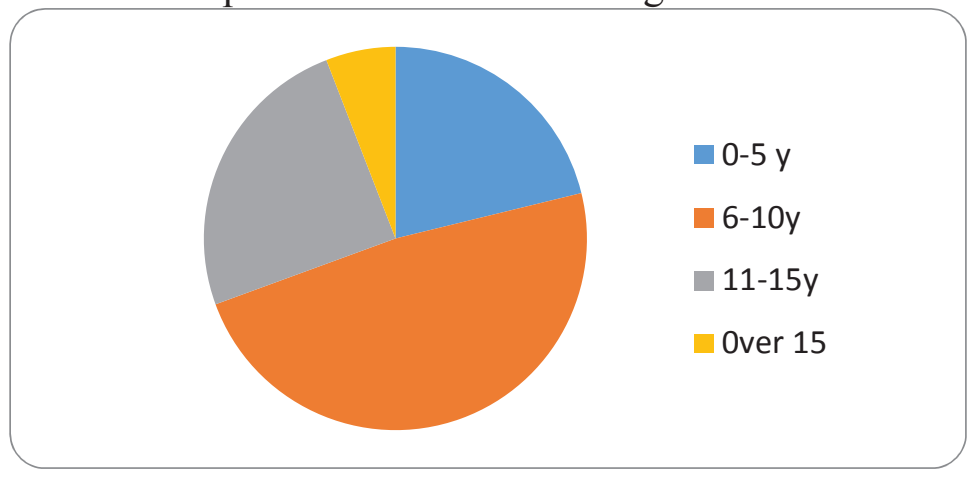

Graph 4. Age groups

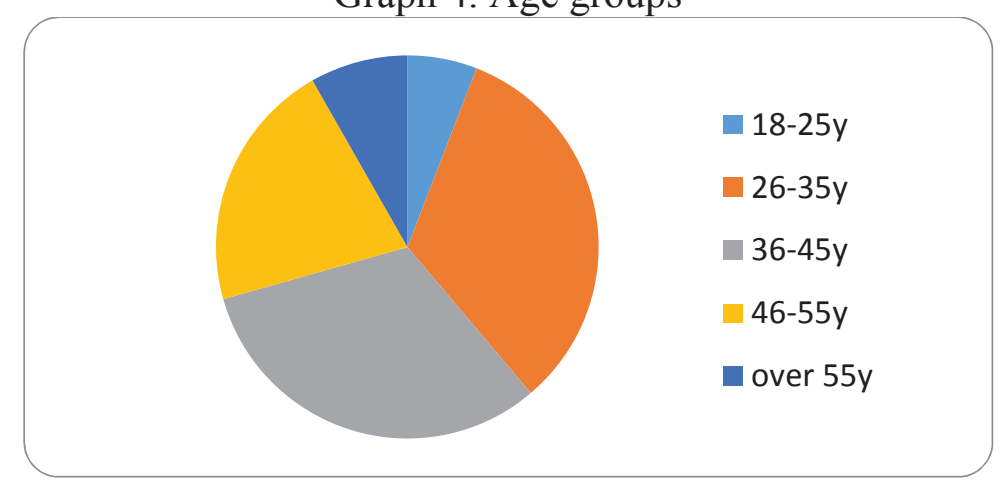




\subsection{Socio-demographic factors and perception of effective communication channels in the organization}

After reviewing the demographic data of respondents, in this aspect will be evidenced differences in gender, age, years of work experience and perception of effective channels of communication in the organization. Respondents were asked to evaluate the communication tools listed in the questionnaire, such as face to face, email, phone calls or memos, from effectivity and frequency perspective within the organization.

\subsubsection{Gender and perceptions about communication channels effectiveness}

The first factor to be considered whether there is differentiation or not regarding the perception of effective communication channels in the organization is gender.

Graph 5. Gender and perception about effective communication channels

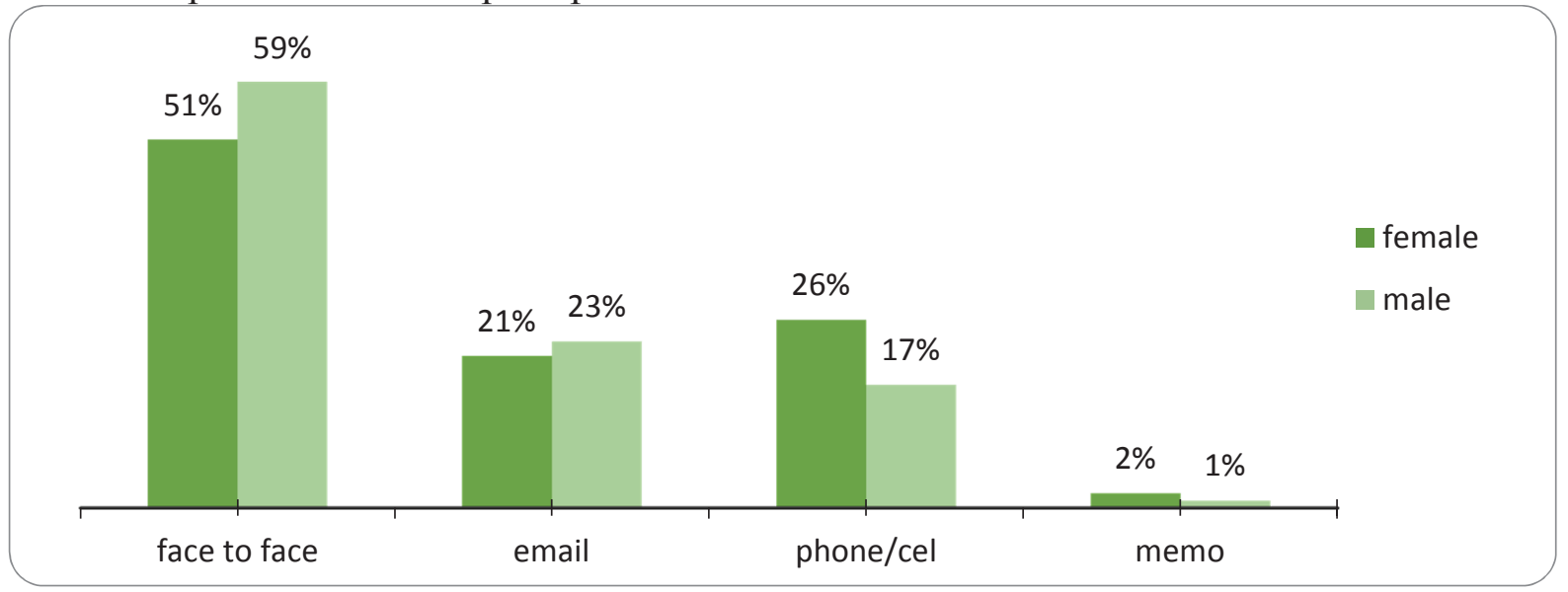

As can be seen from the chart, it seems that the most effective channel, according to the perception of employees regardless of gender is face to face communication. However, it is noticeable that men are the most (59\% of them) who consider this to be the most effective channel compared to women with $51 \%$ of them. There is also gender differentiation regarding the use of email, where it seems to be perceived as the most effective tool for men compared to women ( $23 \%$ of men compared to $21 \%$ of women). The phone is perceived as more effective by women than men (26\% vs. $17 \%)$. Memo compared to other means seems to be perceived as less effective by employees - only $2 \%$ of women and $1 \%$ of men consider it as an effective means of communication in the organization.

\subsubsection{Age and perceptions about communication channels effectiveness}

As far as the age factor is concerned, in graph 6 the most effective means of communication in the organization is perceived the face to face communication, and the less effective memo. Face to face seems to be more effective for people over the age of 55 (91\% of them). Email is considered to be the most effective channel for 36-45-year-old (31\%), while the phone is more effective for ages 18 to 25 years old, (30\% of them). For those older than 36 , the memo is not perceived as an effective means of communication at all. 
Graph 6. Age and perception about effective communication channels

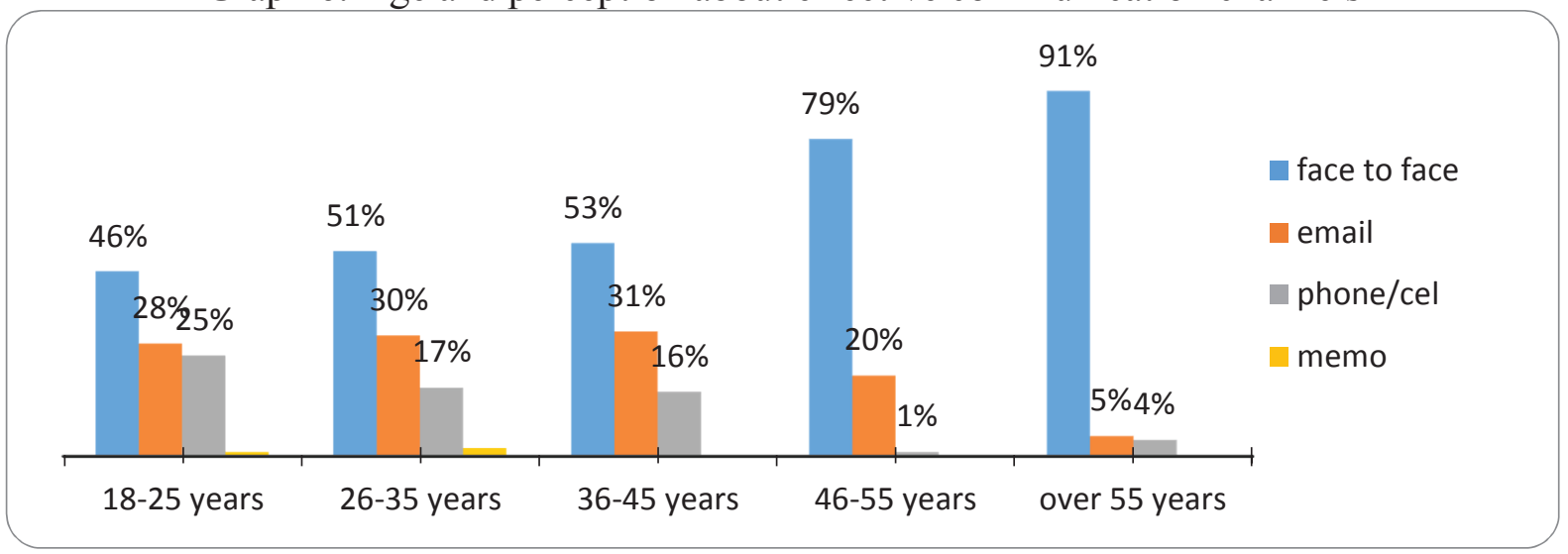

\subsubsection{Working years and perceptions about communication channels effectiveness}

With regard to years of experience in organizations and perceptions about effective communication channels, the data in Graph 8 show that there are differences. For employees claiming to have up to 10 years of work, it is clear that face to face communication is considered as the most effective with regard to other means. A clear majority of $73 \%$ of them value it as such. It is noticeable that with the growing number of years of work experience, it seems that the percentage of those who consider face to face communication as the most effective means falls. While employees over 15 years consider as almost equally important 3 channels: face to face, phone and email. Again, memo is considered as the least effective means of communication, according to this sociodemographic variable, and in some cases it is not considered at all, as in the case of experienced employees from 5 to 15 years.

Graph 7. Working years and communication channels

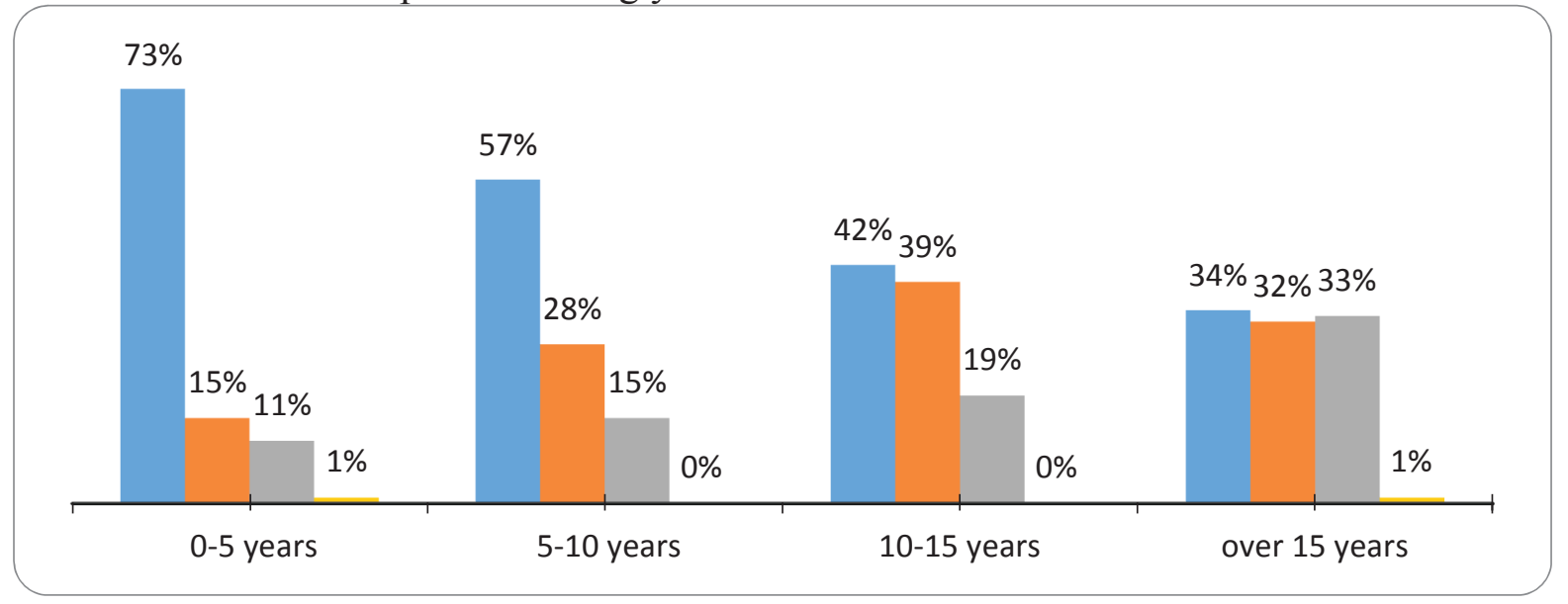

\subsection{Socio-demographic factors and barriers of effective communication}

In addition to the means of communication, in this paper we intend to identify the barriers which, according to employees, impede the realization of effective communication. In the questionnaire, the employees involved in the study have been asked to evaluate barriers ranging from 1 up to 5 (maximum), to the extent that they perceive as obstacles to effective communication. The barriers taken into consideration in this paper are six, and concretely: overload with information, time pressure, organization structure, distraction, emotional state, prejudice. 


\subsubsection{Gender and perception: barriers of effective communication}

Regarding gender and perception of each of the barriers to effective communication in the organization, the evaluations of the respondents are averaged and presented in the graph below.

Graph 8. Gender and barriers of effective communication

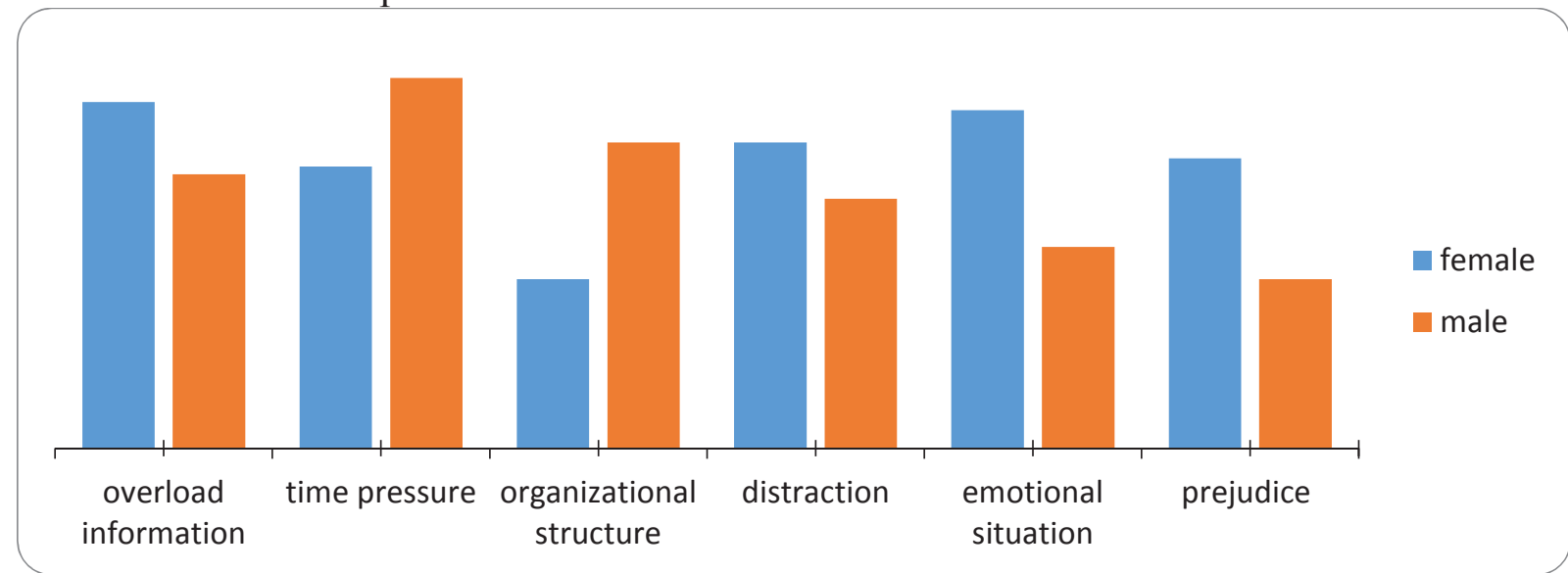

The chart shows that women and men seem to have different perceptions about the barriers to effective communication in the organization. At first glance, women seem to point out the most important barrier as overlapping information, while men seem to perceive the pressure of time. If we analyze one by one the aforementioned barriers, we will see for each of the genders that the most important for women is overload with information that is averaged 4.3 points out of the 5 maximum, to go further with the emotional state averaged by 4.2 , distraction averaged 3.8 , prejudices 3.6 point, time pressure 3.5 point, and finally organizational structure 2.1 point.

Referring to men, based on the averaging of their responses, we see that the most perceived barrier is the time pressure: average of 4.6 points, followed by the organizational structure: 3.8 points, the overload with information: 3.4 points, the concentration: 3.1 points, emotional state: 2.5 points, and finally prejudices with 2.1 points.

From the above, we can say that there are obvious differences, linking gender and perception of the barriers of effective communication. It means that managers should focus their attention on the gender perceived barriers at their employees, in order to avoid obstacles.

\subsubsection{Age and perception: barriers of effective communication}

Regarding the question of whether there are differences in the perception of the barriers of effective communication, depending on the age of the employee, the graph shows that perceptions of barriers to effective communication seem to vary from the age of employees. 
Graph 9. Age and barriers of effective communication

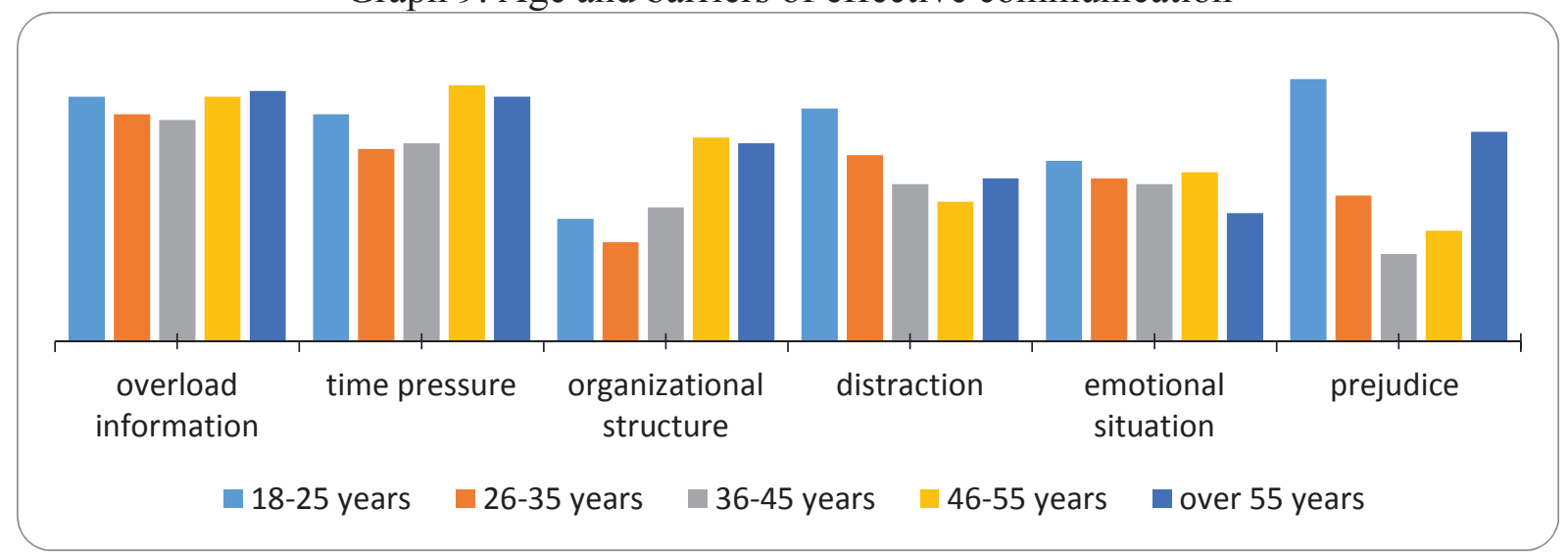

It is noteworthy that workers up to 25 years of age perceive a greater number of barriers compared to others, while fewer barriers in total perceive employees aged 36 to 45 . If we analyze details for each age group concretely, it appears that employees in the age range of 18 to 25 rank as being the first for prejudice, those aged between 26 and 45: overload with information, while over 55 employees perceive mostly time pressure as barrier for effective communication. The organizational structure is the smallest obstacle for the age group 18-25 years and 26-35 years, while the emotional state is ranked last by age groups 36-45 and over 55. Prejudice is ranked last by importance for the age group 46 to 55 years.

If we analyze it in a different perspective, focusing on each barrier and seeing which age group considers it most important, depending on the score estimation, we see that overload with information is considered the main obstacle for people over 55, pressure time for 46-55 age group, as well as organizational structure is perceived as the biggest obstacle by the employees of this age. Meanwhile, the distraction and the emotional state compared to the other age groups are assessed as the most important among the age groups 26-35 years old, while the prejudice of the 18-25 years old group.

Concluding, we can say that age is a strong factor that seems to affect perceptions of the barriers to effective communication. Apparently, given the average age of employees, managers will find it easier to identify and focus more attention on those barriers which tend to be an obstacle to effective communication.

\subsubsection{Working years and perceptions: barriers of effective communication}

The final analysis of this paper consists in identifying the differences that may come as a result of the years of employee experience, as a sociodemographic factor, in relation to the barriers of effective communication in the organization. The processed data are presented in the Graph 10, where the differences can be easily identified. 
Graph 10. Work experience and barriers of effective communication

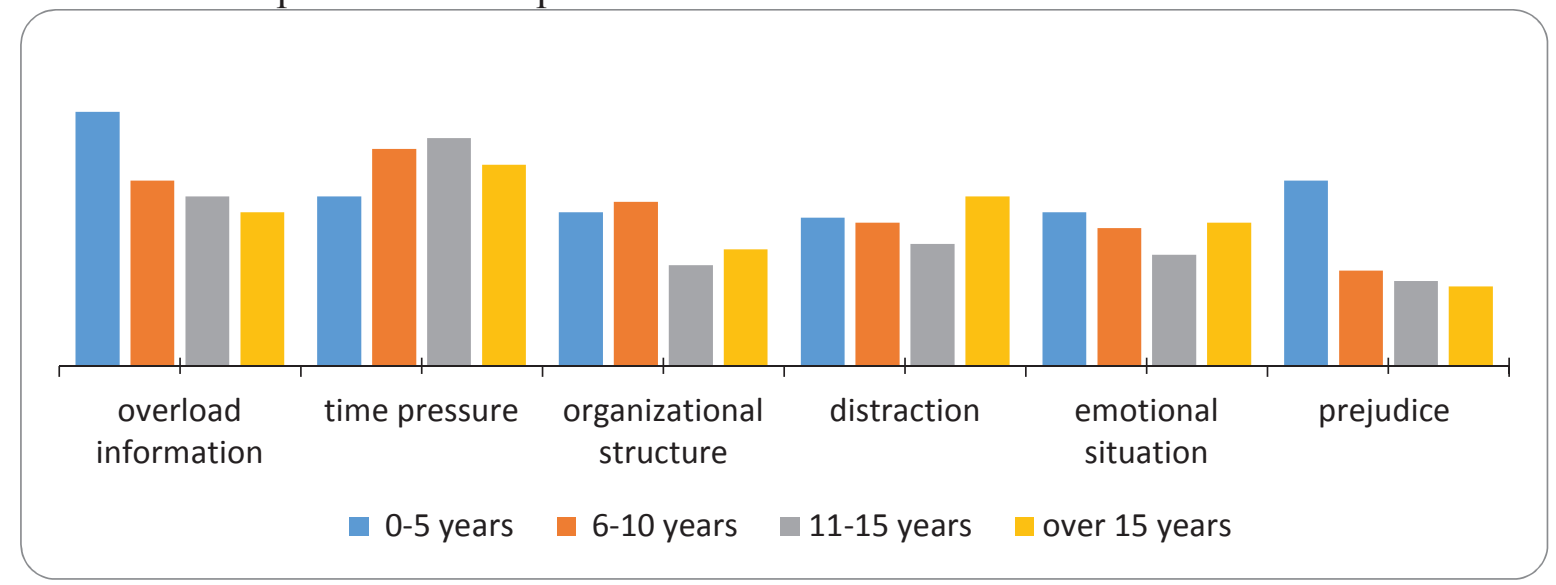

From the graph 10, one could notice the fact that employees up to 5 years of experience consider the most important barrier information overload and give it a considerable rating of 4.8 out of 5 potential. This category evaluates also prejudice as an essential barrier with high score of 3.5 points.

Discussing further the findings, it is visible that employees with 11-15 years of work at the organization consider the time pressure as more important, compared to other age groups. The organizational structure seems to be perceived as a barrier by most of the employees with 6-10 years of experience, while the distraction is more often mentioned by employees with over 15 years of work. Meanwhile, the emotional state is valued more by employees with fewer years of work experience.

At the end of this issue it is to be noted that, despite the fact that employees with different years of experience differ in their perceptions of barriers, those with fewer years of experience seem to perceive a greater number of barriers, compared to other employees.

\section{Conclusions}

In this paper, through the review of literature, attention was drawn to the importance of effective communication for the successful performance of an organization. Effective channels should be used to ensure presence of effective communication within the organization and to identify barriers that might potentially prevent it. Through a descriptive analysis of the data collected by the questionnaire, we attempted to address the research question: how sociodemographic factors such as gender, age, and years of work experience affect the perceptions that employees have for the channels / tools and barriers of effective communication.

From the data analysis, it was evidenced that sociodemographic factors seem to have an impact on employees' perceptions of what they consider as barriers to communication. Concretely, it was concluded that considering gender, women compared to men perceive phone as more effective, the opposite is happening with the use of email. With regard to the years of work experience it is noticed that with the growing number of years of experience in the organization falls the percentage of employees who perceive as the most effective face to face communication. This probably, because with the passing of years the employees know their organization, structures, colleagues, leaders, and culture better. While the opposite occurs with the age factor, with its growth, it increases the perception that face to face communication is more effective. 
As far as barrier analysis is concerned, women generally consider the information overload barrier, while men consider the pressure of time as most problematic. In terms of age and years of work experience, it seems that there are differences for different categories. For example, employees with up to 5 years of work experience as the main barrier considered to be overloading with information, whereas for employees with 5 to 10 years of experience is considered time pressure. In terms of age, it appears that young people up to 25 years of age consider a greater number of barriers as compared to other ages. They consider prejudice as the first barrier to go further in the list with overloading with information and focus, while over 45 employees evaluate time pressure as the most important barrier to achieving effective communication.

Taking into consideration the limitations, this paper however might have an added value from the managerial point of view, because it tends to make aware the managers, that before choosing the channels or means of communicating effectively within the organization, it would be better to select those tools and to address those barriers that are considered as such by the employees, depending on their sociodemographic characteristics.

\section{References}

1. Allen, D. G., \& Griffeth, R. W. (1997). The medium and the Message: The adaptive use of communication media in dyadic influence. Academy of Management Review, 29, 272292.

2. Anderson, C.L. \& Massie, L. (2003). Integrating communications: is the ideal achievable? Corporate Communications: An International Journal, 8(4), 223-228.

3. Bruce Barry and Ingrid Smithey Fulmer The Academy of Management Review Vol. 29, No. 2 (Apr., 2004), pp. 272-292

4. Chia Joy, (2005) "Is trust a necessary component of relationship management?", Journal of Communication Management, Vol. 9

5. Clampitt, PG. \& Berk, L. (2000), A communication audit of a paper mill. In Hargie, O. \& Tourish (eds). Handbook of communication audits for organizations. London: Routledge

6. Clegg, S. R., M. Kornberger, and T. S. Pitsis (2005), Management and Organizations: An Introduction to Theory and Practice, London: Sage

7. De Ridder J. A., (2004) "Organizational communication and supportive employees". Human Resource Management Journal, 09545395, Vol 14, Issue 3, 20-30.

8. Fogelman-Beyer. A. (1999). Are you ready for a communication audit? Public Relations Tactics, 6(8): 19-23

9. Francis, D \& Woodcock, M. (2004). Audits for organizational effectiveness: eight ready to-use audits for organizations. Aldershot: Hants

10. Harris, T. E., \& Nelson, M. D. (2008). Applied organizational communication, theory and practice in global environment. New York: Lawrence Erlbaum

11. Hill, CWL \& Jones, GR. (2001), Strategic Management: an integrated approach. 5th Edition. Boston: Houghton Mifflin Company

12. Hoy, W.K., \& Miskel, C.G. (1998). Educational administration theory, research and practice. U.S.A.: Random House

13. Lesikar, R.V., Pettit, J.D., \& Darsey, N.S. (1999). Communication in business. London: Longman

14. Luecke, R. (2003). Managing change and transition. Boston: Harvard Business School Press

15. Malmelin N., (2007),"Communication capital: Modeling corporate communications as an organizational asset", Corporate Communications: An International Journal, Vol. 12 Iss 3 
16. Trahant B, (2008), Six Communication Secrets of Top-Performing Organizations, The Public Manager, fall 2008, p.68-75

17. Tubbs, S., and S. Moss (2008), Human Communication: Principles and Contexts. 11th ed. Boston, MA: McGraw-Hill Higher Education, cop

18. Watson Wyatt Worldwide. (2004). Connecting organizational communication to financial performance: 2003/2004 communication ROI study.

19. Welch M. and Jackson P. R., (2007) "Rethinking internal communication: a stakeholder approach", Corporate Communications: An International Journal,

20. Wim J.L. Elving, (2005) "The role of communication in organizational change", Corporate Communications: An International Journal, Vol. 10 Issue: 2, pp.129-138, doi: $10.1108 / 13563280510596943$

21. Zaineb A. (2010) "Barriers to effectiveness in an organization and overcoming it" 